\title{
LEVERAGING SOCIAL MEDIA IN HIGHER EDUCATION: A CASE OF UNIVERSITIES IN UGANDA
}

\author{
Drake Patrick.Mirembe [d.p.mirembe@gmail.com],College of Computing and Information Sciences, Makerere \\ University [https:/ / www.mak.ac.ug/about-makerere/contact-information], Jude T. Lubega \\ [judlub@gmail.com],Martha Kibukamusoke[drnamuli@gmail.com],Uganda Technology and Management \\ University (UTAMU) [bttps://utamu.ac.ug], Uganda
}

\begin{abstract}
Social media platforms have transformed the way we live and work. These platforms have opened up new opportunities for service provisioning and business models. Therefore, this paper presents findings of how leading Ugandan Universities are integrating social media in the teaching and learning processes. The researchers adopted a multi-methodology research approach which involved; collecting, analysing and integrating quantitative (surveys) and qualitative (focus group discussions and interviews) research methods. A total of 300 respondents were targeted (students and lecturers) of which 250 responded (196 male and 54 female). The respondents from Makerere University, Uganda technology and Management University (UTAMU) and Makerere University Business School. The results of the study indicated that majority $(94.8 \%)$ of the respondents use WhatsApp, 86.5\% Facebook, 82.1\% YouTube, 53.8\% Twitter, 39.8\% Instagram and $9.2 \%$ snapchat. It was observed that 225 about $91.1 \%$ of student's use social media for learning purposes. A total of 238 respondents use smartphones to access social media. While majority of students on social media platforms use these platforms for learning purposes, majority of lecturers $(37.6 \%)$ never engage students on social media. Therefore, there is a mismatch on social media usage between students and lectures and this calls for the development of social media policies at universities to promote and guide the integration of these platforms in the teaching and learning processes.
\end{abstract}

\section{Abstract in French}

Les plate-ormes de médias sociaux ont transformé notre manière de vivre et de travailler. Ces plateformes ont ouvert de nouvelles opportunités pour la provision des services et des modèles commerciaux. Par conséquent, cet article présente les résultats sur la manière dont les grande et dominante universités Ougandaises sont en train d'intégrer les médias sociaux dans les processus d'enseignement et d'apprentissage. Les chercheurs ont adopté une approche de recherche multiméthodologique impliquant: la collection, l'analyse et l'intégration des méthodes de recherche quantitatives (enquêtes) et qualitatives (discussions de groupe et entretiens). Un total de 300 répondants/ interrogées ont été ciblés (étudiants et enseignants), dont 250 ont répondu (196 hommes et 54 femmes). Les répondants/ interrogées etaient de l'Université de Makerere, l'Université Ougandaise de Technologie et de Gestion (UTAMU) et de l'Ecole de Business de l'Université de Makerere. Les résultats de l'étude montrent que la majorité $(94,8 \%)$ des répondants utilisent WhatsApp; 86,5\% Facebook; 82,1\% YouTube; 53,8\% Twitter; 39,8\% Instagram et $9,2 \%$ Google. Il a été constaté qu'environ $91,1 \%$ des élèves (soit 225) utilisent les médias sociaux pour des fins d'apprentissage. Un total de 238 personnes interrogées utilisent un smartphone pour accéder aux médias sociaux. Pendant que la majorité des étudiants sur les plateformes de médias sociaux utilisent ces derniers pour des fin d'apprentissage, la majorité d'enseignants (soit 37,6\%) n'engagent jamais les étudiants sur les médias sociaux. Pour ce fait, il existe un décalage dans l'utilisation des médias sociaux entre les étudiants et les enseignanrts. Ce qui fait appelle à l'élaboration de politiques de médias sociaux dans les universités afin de 
promouvoir et de guider l'intégration de ces plateformes dans les processus d'enseignement et d'apprentissage.

Key words: Social Media, eLearning, ICT4D, Ugandan Universities, WhatsApp, Universities

\section{Introduction}

The Internet and the Web changed the way information is generated, shared and analysed (Manuel, 2014). Today, every sphere for human life is controlled by information systems consequently, Data and artificial intelligence are becoming the new frontiers of human innovation (Mirembe, 2015; Manuel, 2014). The dependence on information systems means; the speed, storage and retrieval of information in whatever form regardless of the person's location are key factors and issues of concerns. Some of the technology platforms that have emerged over the internet and web are social media platforms. It is very interesting to note that the most profitable technology based companies are data driven companies which provide social media platforms. From Google to Facebook, from twitter to Amazon all have their business models which are data driven Manuel (2014).

The evolution of social media has cut across all facets of society with its positive and negative impacts. Social media has transformed and impacted on; communication, learning, research and education in general (Haydn, 2017). Among the vast variety of online tools which are available for communication, social networking sites (SNS) have become the most modern and attractive tools for connecting people throughout the world (Aghazamani, 2010). Davis et al. (2012; p.82), refer to social media technology (SMT) as web-based and mobile applications that allow individuals and organizations to; create, engage, and share new user generated or existing content, in digital environments through multi-way communication. Through this platform, individuals and organizations create profiles, share and exchange information on various activities and interests. An interesting aspect of social media is that, it is not limited to desktop or laptop computers but could be accessed through mobile devices and smart phones making it very accessible and easy to use. Examples of these social media platforms both on the web and mobile application include; Facebook, Twitter, YouTube, WhatsApp, Instagram, blogs and among others. According to Boyd and Ellison (2007; p.211), "Social networking sites are web-based services that allow individuals to construct a public or semi-public profile within a bounded system, articulate a list of other users with whom they share a connection, and view and traverse their list of connections and those made by others within the system".

By design, social media operational model is based on information; authoring, formatting, sharing and annotation. Therefore, from the operational model of social media, we argue that these platforms are designed to encourage engagement as a means of enhancing the individual world view of things. It is therefore fair to note that, social media operating model by design promotes knowledge generation and learning through individuals' annotations on posts and by generating own opinions and imaginations of their world view. We note that, social media engagements are largely through an informal and conduction in ways which are native to the participants in the conversation. Therefore, it makes sense to integrate these platforms in learning processes of formal educational systems like universities.

\section{Research Objectives and Questions}

The study observed that indeed, both students and lecturers in Uganda universities are using social medial platforms for social engagement, but there is limited understanding on the extent these platforms are being used in formal learning processes. Therefore, this research was aimed at establishing the level of social media usage among students and lecturers in selected Ugandan 
universities as a means of benchmarking practices and development of models of social media integration in university education systems. Some of the key research questions included:

- To what extent are students and lecturers using social media in the teaching and learning processes?

- Which social media platforms are commonly used by lecturers and students for teaching and learning purposes?

- What are the promoting and constraining factors of social media usage in Ugandan universities?

\section{Paper structure}

The rest of the paper is organized as follows; in the next section related works presented. The third section details the methodology used in the study and the fourth section presents the discussion of the findings of the study. The paper ends with a discussion of the emerging conclusions and recommendations in the last section.

\section{Related Work}

According to Griesemer (2014) social technologies are changing the way instructors teach and students learn. Griesemer further observed that, social media tools like Wikis enable collaboration among students but also with their instructors. Tools like social bookmarking, allow users to save and archive entire web pages enabling users to create a personalised searchable internet. A number of studies continue to show that social networks are becoming learning platforms which enable communities of learners to engage with peers and facilitators in a learning process. A number of researchers have found several positive outcomes in the use of social media in learning. A study by Tiene (2000), showed that use of social media improved the level and quality of students' participation in discussions. The author attributed the observations to the level of convenience social media provides to students, the discussions they choose to be part of at a given time and enabling them to articulate their ideas in more carefully thought-out and structured ways. In support of Tiene's (2000) findings, Deng and Tavares (2013) also concluded that online discussions between students and lecturers and among their peers can contribute to the development of their' reflective ability and critical thinking skills. It was observed that online discussion enables weak students to contribute to discussions without fear of expression compared to face-to-face (F2F) interaction. According to Apeanti and Danso (2014), students believed that it would be fun for their lecturers to use social media. Also, their grades would be better if they could contact lecturers through social media and lecturers should hold lecture hours on social media.

Researchers have outlined a number of student benefits in relation to learning outcomes as a result of usage of social network in the teaching and learning processes. Yunus et al. (2012), indicates that students gained more vocabulary and improved their writing skills as a result of their use of social media platforms like Facebook and Twitter. Asad et al., (2012) and Musah (2015) stated the exchange of assignments, resources and discussions on academic work and other issues on social networks among students enhanced students' compliance with timelines. A study by Salvation and Adzharuddin (2014) and Musah (2015) revealed that use of social media platforms in the teaching and learning processes results into improved student academic performance. These observations were also noted by English and Duncan-Howell (2008) in which they used Facebook as a tool to enhance peer support among business education students during their training programme and detected that students' exchanges were mostly of the affective type facilitating group cohesiveness through encouragement and support. 
Menkhoff et al. (2014) and Wheeler (2010) observed that some forms of social media platforms like Twitter and blogs enable both students and instructors to actively and instantly participate in educational activities. These observations are echoed by Dzvapatsva et al. (2014) who argues that social media platforms have a capability to supplement traditional teaching and learning approaches in institutions of higher learning. In their study about the tweeting behaviour of undergraduate students in some universities in Singapore, Menkhoff et al. (2014) found that, Twitter enables students to have "a voice, to be more engaged and to interact more freely with both their peers and the instructor via knowledge sharing and twitter discussions". This means that students who are expectantly captive in traditional approach to teaching, are increasingly offered an opportunity to provide prompt feedback to instructors, an element as noted by Schroeder and Greenbowe (2009) and Jones (2015; p.93). Indeed, the use of social media in teaching and learning leads to the much treasured student-centred learning approach. The notion of 24/7 in this context simply suggests that embracing social media enables students and lecturers to interact outside the formal learning time with more flexibility, making learning process fun and intuitive.

In addition, social media filling pedagogical gaps in higher education including open publishing, new communication styles and texts, expressing personal identity and experience, co-creation and collaboration, and content management as observed by De Wever et al. (2015), Terrell et al. (2011) and Waycott et al., (2010). According to Calli et al. (2013), content effectiveness had a significant effect on perceived usefulness by the users. Lee and Faulkner (2011) note that content richness in e-learning has been identified as extrinsic factors in the inquiry model of e-learning and observed that scenarios and illustrations deliberately enhance learner motivation leading to improved learner outcomes. Thus, social media provide a wealth of content in various formats, and the various points of view enhance the students understanding of concepts.

While in general, the use of social media in teaching and learning has a position in contributing to learner outcomes, Osborne (2011) noted that the use of social media in learning should be guided by appropriate policies to minimize the negative efforts of these platforms. Osborne (2011) noted that social media necessitates faster, less formalized processes than traditional print or online media, it can be beneficial to create appropriate organizational policies, procedures, and guidelines. These policies must acknowledge both the risks and benefits of social media. It is important that the organization accepts and understands those guidelines.

\section{Research Methodology}

The researchers adopted a mixed methods research approach involving both qualitative and quantitative methods of data collection and analysis. In order to gain an in-depth understanding on the issues under investigation research conducted both primary and secondary data collection and analysis. The secondary data analysis used an explorative literature review approach which involved a review of 50 peer review publications. Therefore, this section describes the research process and approaches which include; the selection of respondents, development of tools and the means through which data was collected and analysed.

Given the nature of the study, respondents to this study were selected using a purposive sampling technique. According to Weisberg et al. (1989), a purposive sampling technique is a nonprobability technique of establishing a sample space for a given study. Thus respondents to this study were selected on their unique qualities that made them likely to provide the desired opinions and experiences about the use of social media in teaching and learning. The participants were selected from universities in Uganda (Makerere University, College of Computing and Information Sciences, Uganda Technology and Management University (UTAMU), Makerere 
University Business School and Kampala International University, which are promoting the use of e-Learning.

At least a total of 300 respondents were targeted for the study and a total of $250(\sim 83.3 \%)$ responded to the study, a response rate which was considered sufficient to represent opinions of the wider university student community. The primary data was collected using; survey questionnaire, key informant interviews and focus group discussions. The key informant interviews were used to gain opinions from selected lecturers who had a Facebook and twitter presence. While the focus group discussions where used as a validation step among student respondents largely at Makerere university and UTAMU. The survey questionnaire was deployed online which made it easier and convenient for respondents to participate. The data was first cleaned for clarity, completeness and then coded before analysis. The quantitative data was analysed using SPSS using descriptive statistics while qualitative data was analysed using thematic content analysis. The meanings and implications arising from study as well as participants' responses were then explored and synthesized for presentation.

\section{Study Results and Findings}

The population considered for the research included a total of 250 participants of whom $78.4 \%$ were male and $21.6 \%$ female. These participants were from several higher institutions of learning in Uganda which included; Makerere University (Mak) Uganda Technology and Management University (UTAMU), Makerere University Business School (MUBS) and Kampala International University (KIU). It was also noted that majority of respondents were between the age of 23-27 years, followed by 18-22 years and 28-32 years respectively. The Figure 1 below describes the gender details and age bracket of all the respondents.
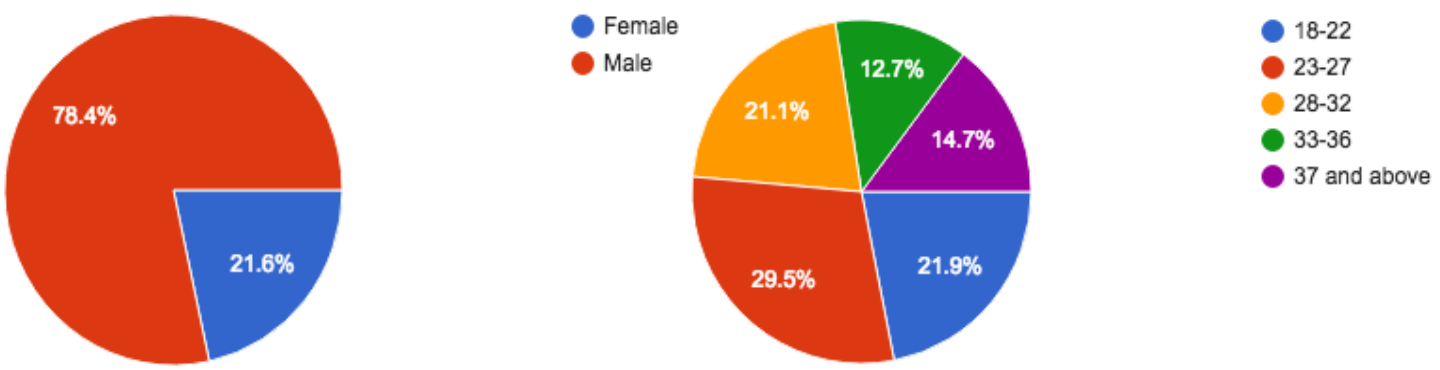

Figure 1. Gender and Age Range of Respondents

In terms of highest level of education of student respondents, $52.6 \%$ were at the bachelor level, followed by postgraduate level $(41 \%)$ and diploma and below at $(6.4 \%)$. It was also noted that majority of the students who responded to the research were from the business based courses $(61.8 \%)$ and the rest $31.8 \%$ from the computing and engineering courses. Figure 2 describes the field of study of student respondents and their level of education.
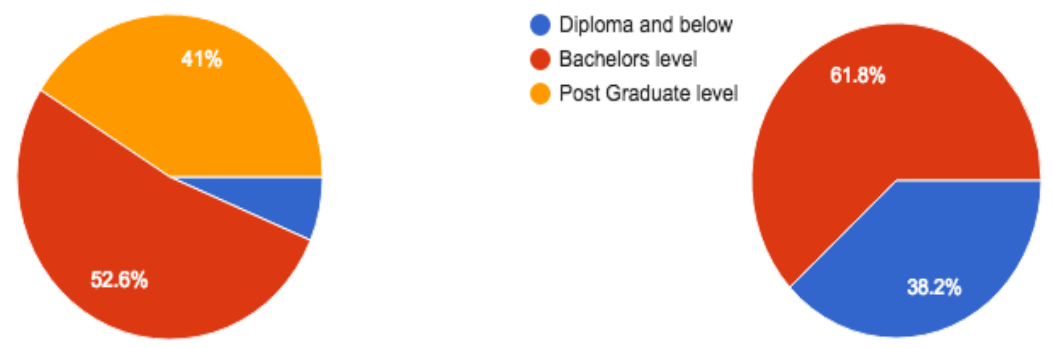

Figure 2. Field of Study and Level 


\section{Type of Social Application Used}

The respondents were asked about the type of social media applications they use while undertaking their educational activities and the following results were realised. It was noted that majority $238(94.8 \%)$ of the respondents indicated to have been using WhatsApp, 217 (86.5\%) were using Facebook, 206 (82.1\%) were using YouTube, (135) 53.8\% were using Twitter, 99 $(39.3 \%)$ students were using Instagram and $23(9.2 \%)$ were using snapchat. However, there were also other applications that were found to be in use among the students. The Figure 3 clearly indicates that majority of the university students who were using social media applications used more WhatsApp and Facebook for their social interaction.

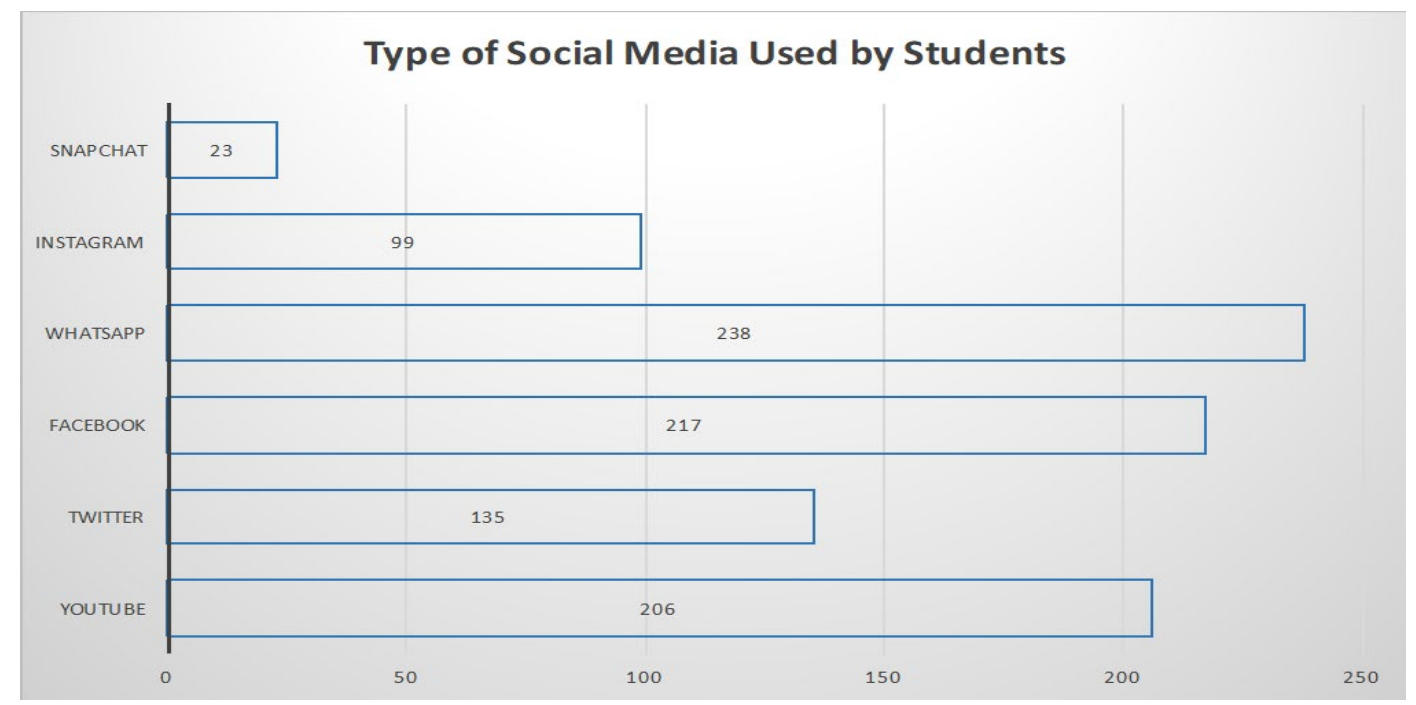

Figure 3. Types of Social Media Applications Used by Students

The interaction with lecturers through key informant interviews and focus group discussions with selected students revealed that YouTube was mainly used for accessing educational content in form of videos by both students and lecturers. Also majority of lecturers especially those in computing and engineering fields indicated that they post their own content on YouTube for other people to view.

As noted by one lecturer "Videos from YouTube especially those with animations help me to learn, how to explain and illustrate complex concepts to my students in a simple way". Majority of Lecturers through key informant interviews also indicated that they use WhatsApp mainly to pass on reminders and notifications to students. As one lecturer from Makerere University indicated "I find social media interaction with student's time consuming and accordingly I use WhatsApp mainly to send notifications and reminders to students"

When the students were asked about the time they spend on social media on a daily basis, the results of the survey revealed that; $20.4 \%$ spend less than one hour, $45.2 \%$ indicated they spent less than 3 hours, $17.6 \%$ between $3-5$ hours and $16.8 \%$ for more than five hours. What should be noted that $34.4 \%$ of all the students who responded to the research spent more than 3 hours on social media a day. This is a clear indication that students are spending quite some time on social media and therefore institutions should devise means of using the social media applications for educational purposes. For example, WhatsApp which is the most commonly used application could be used for students' group discussions and communicating vital information. Facebook could also be used for availing content for the students, discussions on a given topic and chatting between teachers and students. Future research should focus on understanding what time of the 
day students access most of these social media applications in order to support their integration within the educational system.

\section{Social Media Access Devices Used}

The research also sought to ascertain the type of devices students were using to access the social media applications. The survey results show that majority 238 (95.2\%) were using their mobile phone followed by computers with $180(72 \%)$ as illustrated in Figure 4.

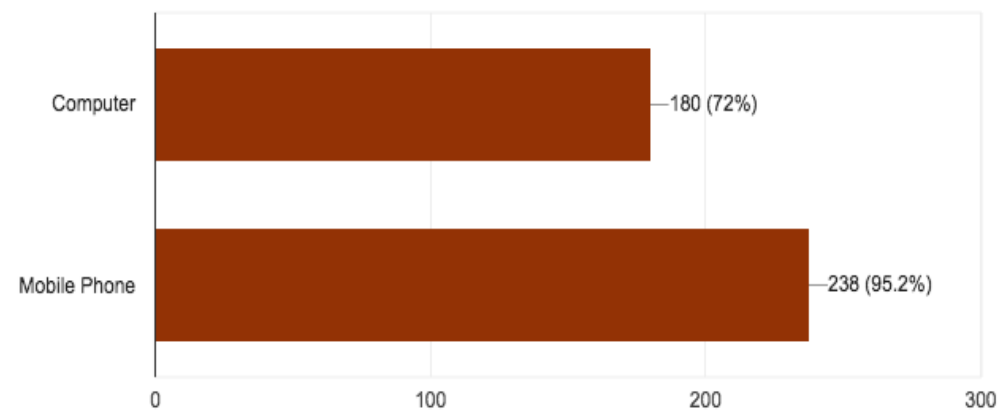

Figure 4. Devices Used for Accessing Social Media Applications

Also, the results of key information interviews among Lecturers revealed that majority of lecturers who access social media application use both mobile phones and laptops. As noted by one lecturer from UTAMU "smart phone keyboards are small and consume too much time when typing, therefore I mainly use my laptop when engaging students on social media platforms"

These results that access to basic hardware for social media engagement was no longer a serious problem because $95.2 \%$ of students who responded and 100\% of lecturers had access to either a smart mobile phone or computer. With the current trend of internet costs going lower and lower in the country it is fair to conclude that accessibility to social media platforms among students and lecturers is going to increase.

\section{Purpose for Social Media Access by Students}

Having noted that most students access social media using mobile phones the research sought to find out the purpose of their social media usage. The results indicate that majority of the students $(91.1 \%)$ access social media platform for learning, followed $(82.6 \%)$ who access for news updates, $(78.5 \%)$ access the platforms to engage friends and family and lastly $(74.1 \%)$ access social media platforms for entertainment purposes as shown in Figure 5. These results present an interesting finding that the students access social media majorly for educational purposes. These results are similar with those of the focus group discussions with students who participated in the study. The results revealed that majority of students' access social media for learning purpose either formally or informally. As noted by one student in the FDG "social media has helped me learn about personal hygiene and online marketing skills ". Interestingly, the results of key informant interviews among lecturers revealed that majority of lecturers' access social media to get; news updates, followed by entertainment and engagement, and for educational purposes is last. 


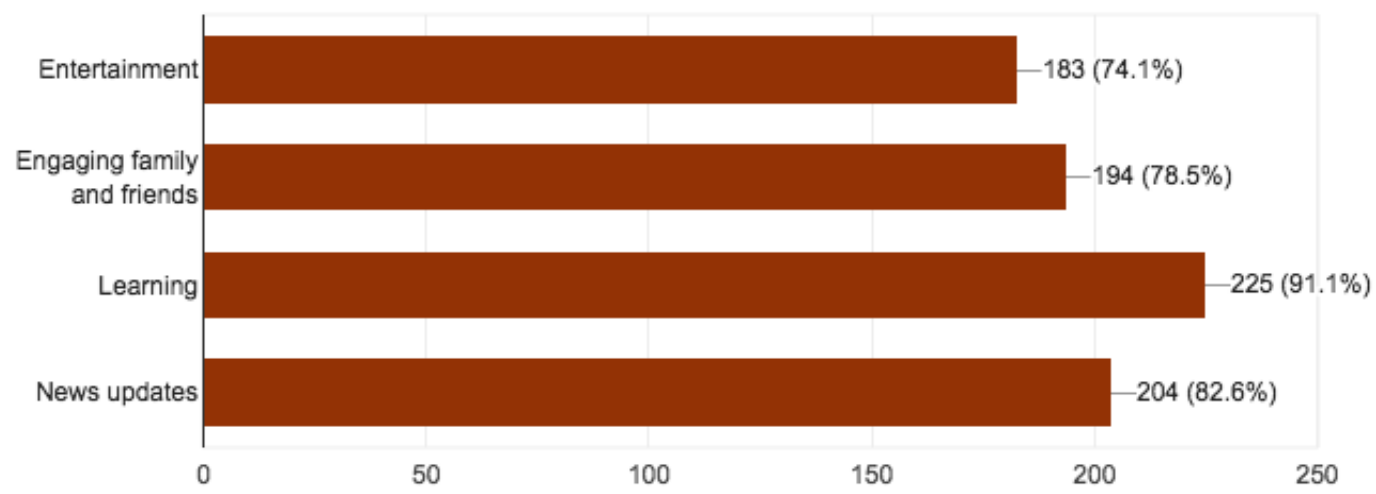

Figure 5. Purpose for Social Media Access by Students

The desire to use social media for learning purposes by students can be attributed to the growing availability of free educational resources online, but also the convenience of engagement the platforms do provide to students. As noted by one lecturer through key informant interviews; "social medial provides a good opportunity for students to relate with external content resources, have access to some of the best teachers/authorities in the subject matter and also share experiences with other students from across the world". The Lecturers' observation was echoed by majority of students during FGD's which noted that availability of free educational resources on platforms like YouTube and WhatsApp was a key motivator for their access to these platforms. While results show the growing use of social media for education purposes especially among students, the mismatch of intention of use among students and lecturers calls for development of; policies, strategies and frameworks through which social media applications can be integrated into teaching and learning.

Since majority of students indicated they use social for learning purposes, the study thought to establish the average amount of time a day actually spent on social media learning activities. The results of the survey show that (41\%) of the students spend between 1-3 hours on social media for learning purposes, followed by those who used less than an hour (36.9\%), 14.5\% spend between 3-5 hours and 7.6\% spend more than 5 hours. It should be noted that more than half of the students who responded to study (55.5\%) used between 1-5 hours for social media educational learning. The results of key informant interviews among lecturers revealed that majority spend about 1 hour on social media compared to 3 hours majority of students spend. This is a significant result, given the fact that on average students in Ugandan Universities have about 3 contact hours / Lecture hours a day. This implies that social media provides one of the avenues of continued learning for students beyond the 3 hours of face to face lectures provided at these universities. Given, the level of social media usage in higher institutions of learning as indicated by these results, the government needs to review some policies concerned with social media especially the social media tax as a way of promoting the integration of these technologies in learning. The FGDs with students revealed that most of the free educational resources accessed on these platforms are foreign and lack local context and case studies especially in business courses. This, implies there is need to promote the development of local education resources and make them available to students.

\section{Level of Usage of Key Social Media Platform for Learning Purposes}

The results of the survey among students on the usage of most popular social media platforms for learning purposes revealed that; more than $75 \%$ of students indicated to using YouTube at high levels, about $40 \%$ use WhatsApp at high levels, $83.1 \%$ indicated that they use Twitter at low levels, about $90 \%$ use Instagram at low levels and about $20 \%$ use LinkedIn for Learning as illustrated in Figure 6. 


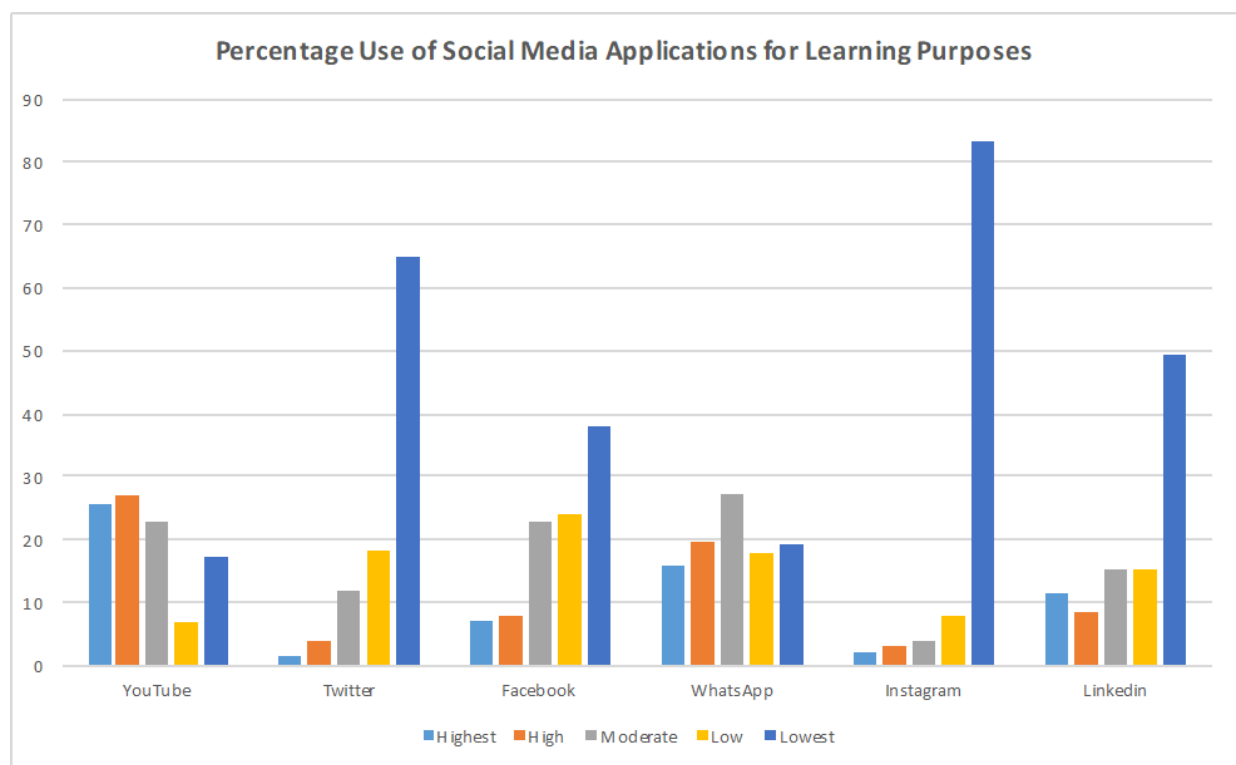

Figure 6. Students Use of Social Media for Learning Purposes

The key informant interviews among lecturers revealed that most Lecturers mainly use YouTube for learning purposes, which is the same case with most of the students. As illustrated on Figure 6; Instagram, Twitter and LinkedIn are the least used platforms for learning by students. This result is not surprising as LinkedIn and Twitter are largely used by professionals for engagement as opposed to sharing large amounts of information. While Instagram is largely used for social engagement and entertainment. Therefore, there is need for educational institutions to further participate in the local content development but also develop policies that promote the usage of social media in learning.

In learning processes of higher education institutions, research plays a critical role in the knowledge generation and accordingly, the research also sought to find out the usage of most popular social media platforms for research purposes among students and Lecturers. The results indicate that; YouTube (87.9\%), WhatsApp (43.3\%), Facebook (33.3\%) are most used by students for research respectively as show in Figure 7. The interviews of lecturers revealed that majority of them again use YouTube for research purposes, sighting the richness of content on the platform. As noted by one Lecturer from Makerere University Business School (MUBS) "YouTube provides a wealth of content in various formats and illustration and most of key authorities in my areas of research have videos discussing their theories which illustrated concepts better than journals papers and books". As shown in Figure 7; YouTube, WhatsApp and Facebook once again have been found to be more usable tools in learning processes especially during research however, their effectiveness in contributing to learner outcomes in settings like Uganda's higher education sector needs to be further investigated. 


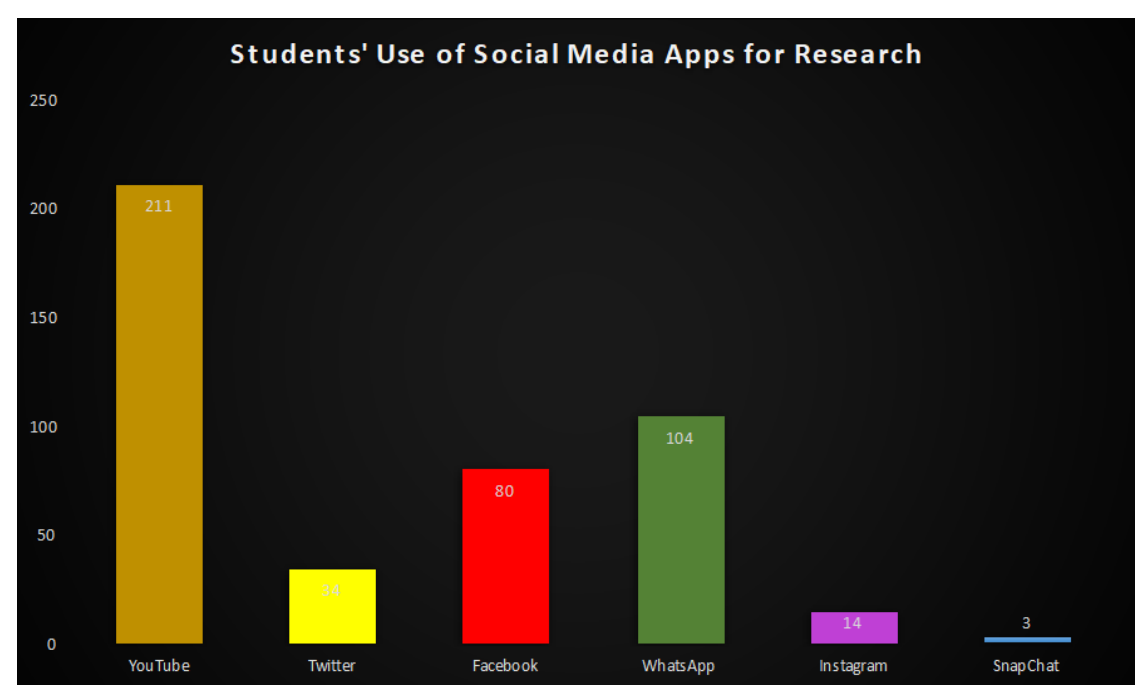

Figure 7. Social Media Tools Used for Research Purposes by Students

Discussions and collaborative engagement are a whole mark of constructivism form of learning which is mainly practiced by online communities. Therefore, the study sought to establish the most commonly used social media platforms by students to conduct discussions with peers. The results as illustrated in Figure 8 show that WhatsApp with $88.9 \%$ responses and Facebook with $53.3 \%$ responses are mostly used by students to conduct discussions. These results clearly inform how educational institutions should take interest in integrating of social media within learning processes. The results of FGD with students as to why they use WhatsApp and Facebook more for discussion, it was revealed these two platforms provide timely one-on-one engagement, but also facilitate group discussion as opposed to other platforms. As noted by one student in an FGD at UTAMU "WhatsApp enforces accountability with message delivery and read feature, which encourages lazy and weak members of the group to participate in the discussions".

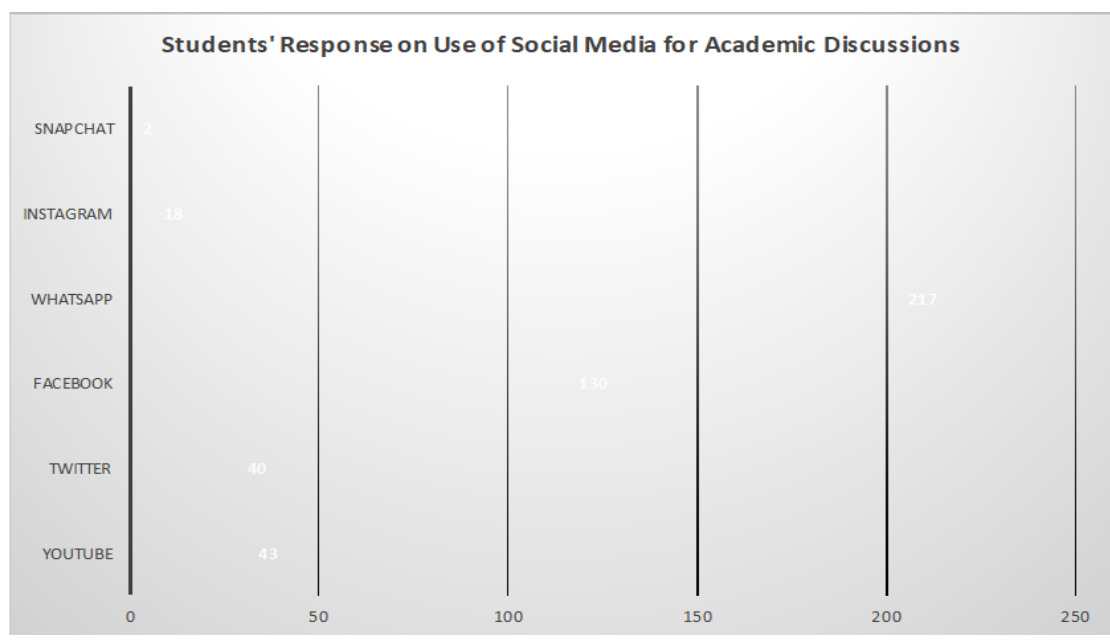

Figure 8. Social Media Tools Used for Discussions by Students

The learning process involved a number of activities, therefore the study sought to establish the usage of social media applications in other learning activities like; engagement, assessment, notification and updates. The results of the survey as illustrated in Figure 9 show that WhatsApp is the most used platform for assessment, notification and engagement with the average response of above $75 \%$. The second commonly used is Facebook followed by Twitter. It is also true that these applications are the most common ones amongst the youth. Academic institutions should devise means of tapping into the opportunities presented by these applications to provide a ubiquitous form of teaching and learning. 


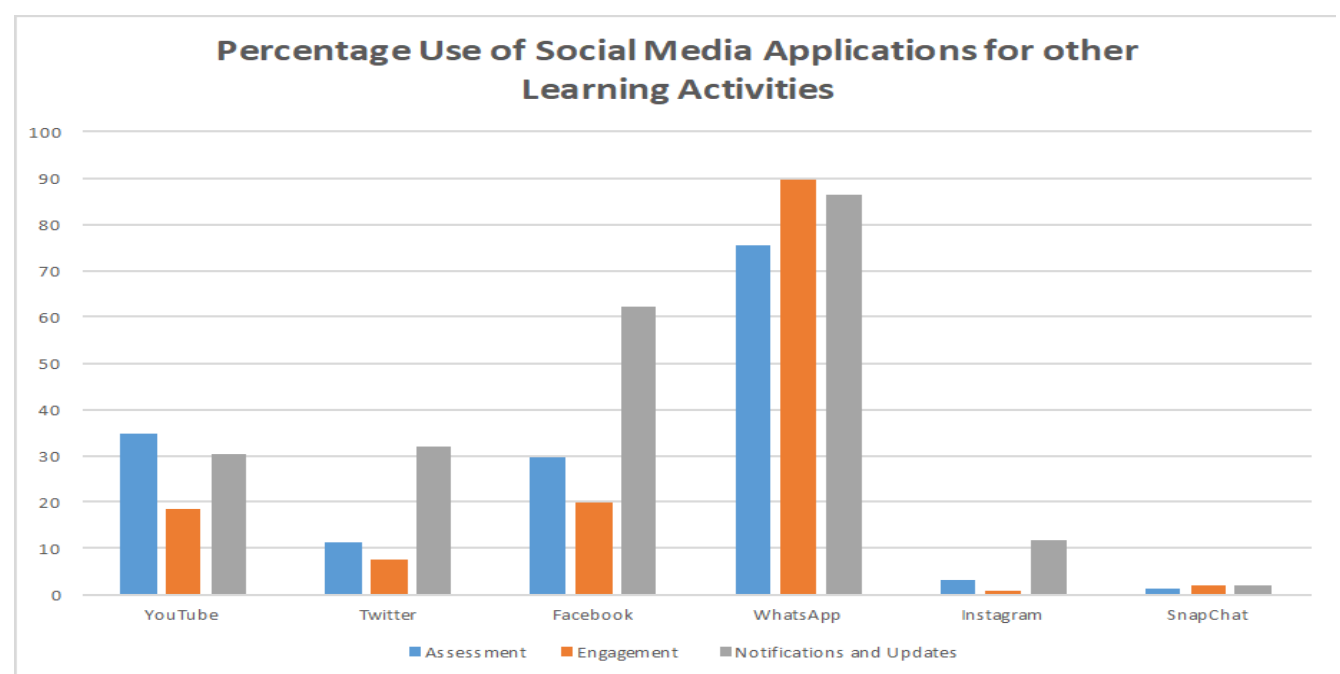

Figure 9. Social Media Usage by Students for; Assessment, Notification and Engagement

Since the students had indicated that one of the main activities they used social media for was for discussions, it was important to know if the lecturers used social media to engage with them. The results from the survey among students indicated that majority of the respondents (50.85) indicated that their lecturers often engaged them on these platforms, 39.3\% of students indicate that lecturers don't engage them on the platforms at all, while $11.5 \%$ indicate their lecturers engage them more often. The research can confidently conclude that at least $62.3 \%$ of the entire students who responded to the study indicated that lecturers did engage on social media platforms as illustrated in Figure 10. The interview with lecturers on the level of engagement with students on social media revealed that, majority of lecturers noted that social engagement with students is time consuming given the number of students involved. As observed by one Lecturer "I have a class of 150 students, when we start a WhatsApp discussion by the time 30 students have submitted their posts, it's hard for me to keep track of the conservations, may be its good for smaller classes or closed group of people like a research team".

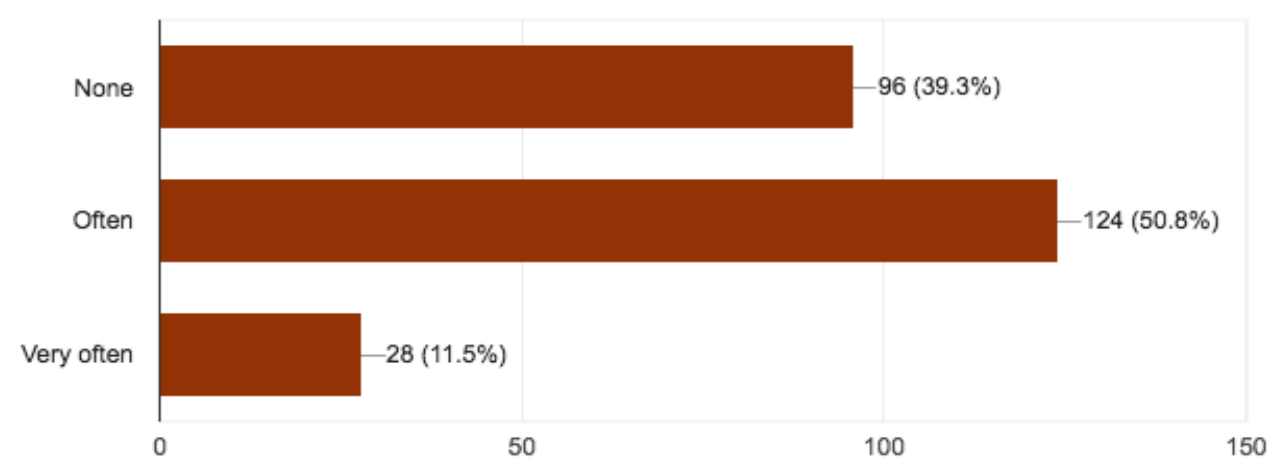

Figure 10. Level of Lecturers Engagement of Students on Social Media

Given the results in Figure 10, academic institutions should therefore formerly adopt the use of social media for some learning activities that they feel comfortable to engage students putting into consideration the challenges raised by lecturers.

Since the use of social media applications was very commonly used amongst the students, the researchers sought to find out if the students used these applications for sharing information amongst themselves. Majority of the students indicated that they used the social media applications to share information amongst them once a day $(64.5 \%)$ followed by once a week $(27.3 \%)$, then once a month $(8.2 \%)$ and lastly never $(5.3 \%)$ for class purposes. In any educational activity, sharing educational information is a core activity and therefore if social media 
applications are used for this same purpose, then they are core to the educational process. The Figure 11 describes rates at which the students use social media applications for sharing class related information at their institution of learning.

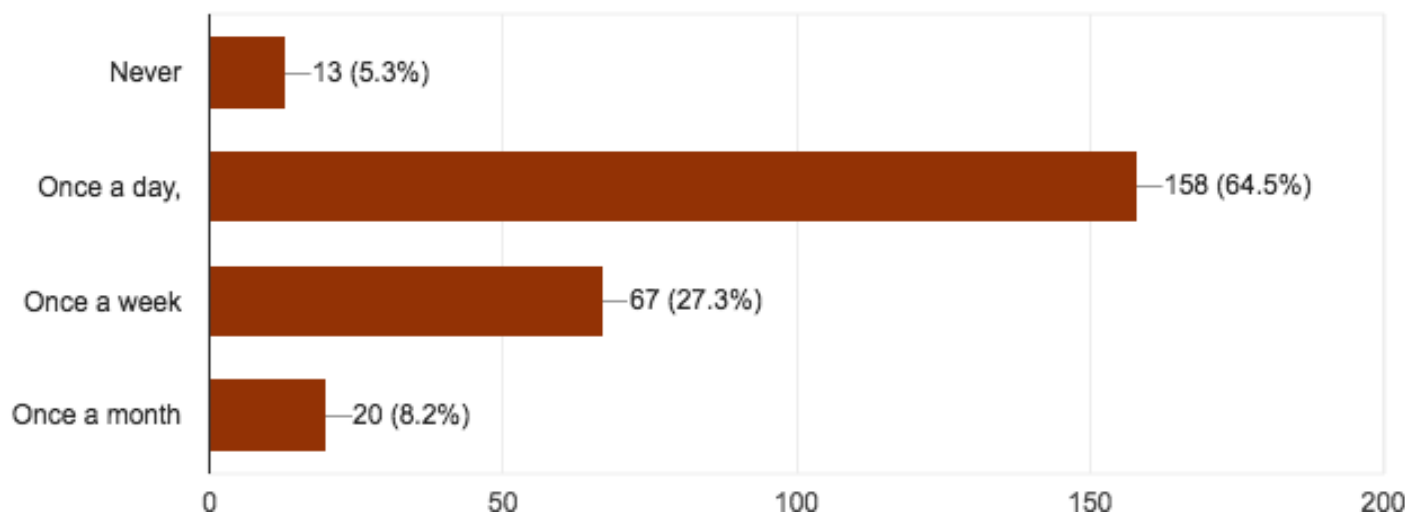

Figure 11. Frequency of Students Use of Social Media to Share Class Related Information

Since majority of students indicated to use social media can be used also for learning purposes, the study sought to establish the level of social media usage by lecturers to engage students. The results revealed that over a third of lecturers $(37.6 \%)$ have never engaged students on social media, $30.2 \%$ engaged them once a week, $18.8 \%$ once a month and $16.7 \%$ once a day. It is evident that about $63 \%$ of lecturers had engaged the students on social media in relation to their learning activities as illustrated in Figure 12. The results of the key informant interviews among lecturers revealed that the use of social media in learning among lecturers is largely informal and all universities that participated in the study did not have a social media policy. As noted by one lecturer from Makerere University "the university e-Learning system failed to take off, because of lack of a policy. Now the current use of social media to facilitate learning is a personal initiative by lecturers and there are no incentives to use it. The lecturers' efforts are largely measured by the number of lecture hours a week, which do not factor in online engagements". This study concludes that the integration of social media into learning processes in universities in Uganda is largely constrained by lack of policy to guide the use of these platforms.

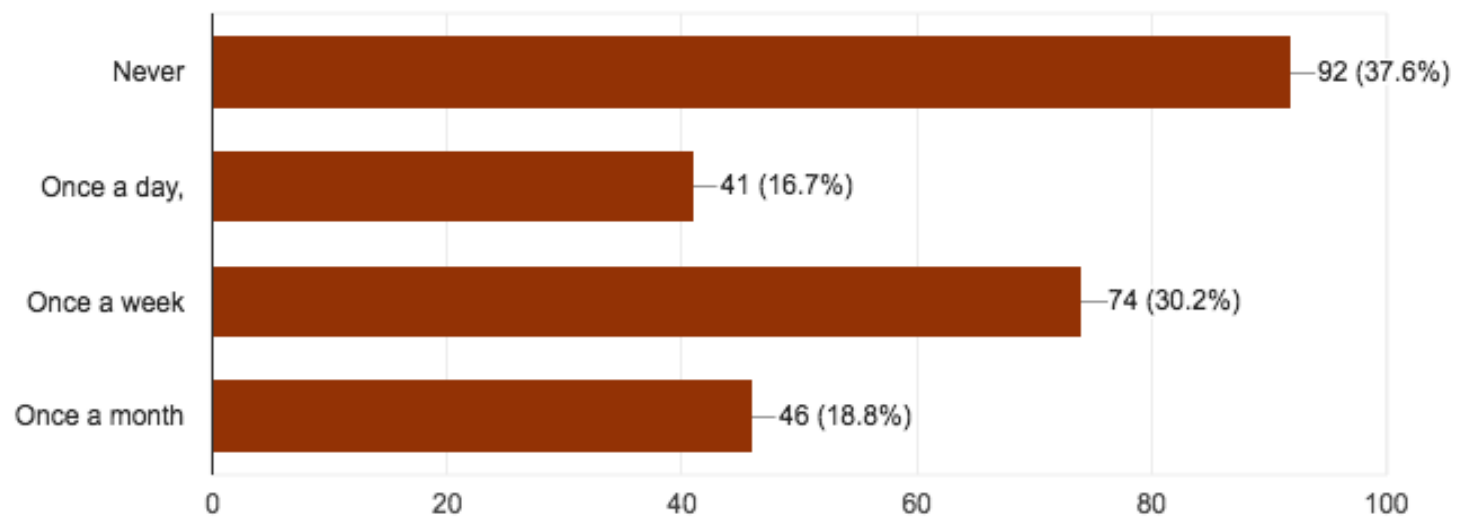

Figure 12. Use of Social Media by Lecturers in Engaging with Students

It was also important to understand the extent to which social media contributed to enhancing students' learning experience. From the analysis, it was found out that $35.2 \%$ of the students felt that social media enhanced their learning experience followed by $31.6 \%$ to an extent, then fairly extent at $26.7 \%$ in enhancing their learning experience. So, it is clear from the results that majority of the students who responded had actually received some enhancement from the social media towards their learning experience. Since the students prefer to work within a space that 
offers them the interactiveness and flexibility during their learning. The Figure 13 shows students' response on the extent to which social media enhanced their learning experience.

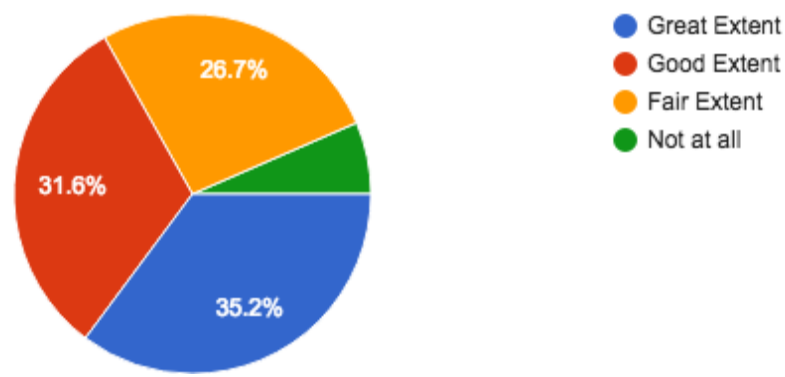

Figure 13. Reponses of Student's on Social Media Ability to enhance their Learning Experience

Engaging further students during the FGDs to know what they would want the Lecturers to use the social media to enhance their learning, these two quotes stand out

"Lecturers should continue using social media to improve communication with students especially through WhatsApp groups to alert on new information especially for distance students". Recommend by a student at UTAMU.

"Lecturers especially those facilitating graduate students use Whats App to communicate changes in lecturer schedules in a timely manner, but also Makerere University should allow graduate students to defend their proposals using Skype and other video mediated social media tools" observed by a student at Makerere University, College of Computing and Information Sciences.

Another student at MUBS noted "Most of the content on YouTube is foreign content and lacks contextual case studies. So our lecturers should develop and publish local content on YouTube to enable easy access by students"

The response from the students clearly indicates that some social media platforms can already be integrated into their teaching and learning delivery framework since they are already in use by both students and staff. However, universities need to do more to harness the opportunities provided by these platforms.

\section{Conclusion and Recommendations}

Social media platforms are evolving day by day and are becoming very popular amongst the university students globally and in Uganda than ever before. As evidenced by results of this study, it is fair to say that it is becoming a common practice for both students and Lecturers to interact on social media as a mean of enhancing the learning experience. The study revealed that participating universities in the study did not have a social media integration framework in learning processes and this in part is constraining the full exploitation of these platforms. The results revealed that majority of the students are accessing social media and mainly so for learning purposes. The study revealed that the most commonly used social media platform for learning purposes was YouTube followed by WhatsApp. While the use of social media for learning purposes was very significant, it was observed that the use of these platforms by Lecturers to facilitate learning the process was low.

From this study a number of recommendations have emerged. Universities need to develop social media policies and frameworks for their integration into the teaching and learning processes. Given the significant level of usage of social media by students in higher institutions of learning, the government of Uganda should review social media policies which constrain the 
integration of these platforms in the learning processes. Lecturers need to develop local content and associated educational resources and make them available on social media platforms like YouTube. Finally, students and lecturers noted that the time spent on the social media engagement is currently not accredited by educational systems, therefore universities need to review and acknowledge time invested in social media engagements for learning purpose by both students and Lecturers.

\section{References}

1. Aghazamani, A. (2010). How do University Students Spend Their Time on Facebook? An Exploratory Study. Journal of American Science, 6, 730-735.

2. Al-Samarraie, H., Teo, T., \& Abbas, M. (2013). Can structured representation enhance students' thinking skills for better understanding of E-learning content? Computers and Education, 69, 463-473. http://dx.doi.org/10.1016/j.compedu.2013.07.038

3. Apeanti, W. O., \& Danso, E. D. (2014). Students' Use of Social Media in Higher Education in Ghana. Innovative Journal, 3(1), 3-9.

4. Calli, L., Balcikanli, C., Calli, F., Cebeci, H. I., \& Seymen, O, F. (2013). Identifying factors that contribute to the satisfaction of students in e-learning. Turkish Online Journal of Distance Education, 14(1), 85-101.

5. Capece, G., \& Campisi, D. (2013). User satisfaction affecting the acceptance of an e-learning platform as a mean for the development of the human capital. Behaviour \& Information Technology, 32(4), 335-343. http://dx.doi.org/10.1080/0144929X.2011.630417

6. Cappel, J. J., \& Hayen, R, L. (2004). Evaluating e-learning: A case study. Journal of Computer Information Systems, 44(4), 49-56.

7. Davis, C. H. F., Canche, M. S. G., Deil-Amen, R., \& Rios-Aguilar, C. (2012). Social Media in Higher Education: A Literature Review and Research Directions. Arizona: The Center for the Study of Higher Education at the University of Arizona and Claremont Graduate University.

8. Deng, L., \& Tavares, N, J. (2013). From Moodle to Facebook: Exploring Students' Motivation and Experiences in Online Communities. Computers and Education, 68, 167-176.

9. Deng, L., \& Yuen, A. H. (2011). Towards a framework for educational affordances of blogs. Computers \& education, 56(2), 441-451.

10. De Wever, B., Hämäläinen, R., Voet, M., \& Gielen, M. (2015). A wiki task for first-year university students: The effect of scripting students' collaboration. The Internet and Higher Education, 25, 37-44.

11. Dzvapatsva, G. P., Mitrovic, Z., \& Dietrich, A. D. (2014). Use of social media platforms for improving academic performance at Further Education and Training Colleges. South African Journal of Information Management, 16(1).

12. Griesemer, J. A. (2014). Using social media to enhance students' learning experience. Quality approaches in higher education, 1(3), 8-11.

13. Inayatullah, S. (2017). Teaching and Learning in Disruptive Futures: Automation, Universal Basic Income, and Our Jobless Futures. Knowledge Futures: Interdisciplinary Journal of Futures Studies, 1(1).

14. Manuel, C. (2014). The impact of the internet on society: A global perspective. MIT Technology review. 
15. Menkhoff, T., Chay, Y. W., Bengtsson, M. L., Woodard, C. J., \& Gan, B. (2014). Incorporating microblogging ("tweeting") in higher education: lessons learnt in a Knowledge Management Course. Computers in Human Behavior.

16. Mirembe, D. (2015). The threat nets approach to information system security risk analysis. Groningen: University of Groningen, SOM research school.

17. Musah, A. (2015). Social Media Network Participation and Academic Performance in Senior High Schools in Ghana. Jeffrey Mingle Lancaster University Ghana.

18. Osborne, N. (2011, December 20). Using social media in education, Part 1. Opportunity, Risk and Policy. IBM [Blog post]. Retrieved from https://www.ibm.com/developerworks/library/wa-ind-educ-social-media1/

19. Rosli, M. S., Saleh, S. N., Aris, B., Ahmad, M. H., Seijzi, A. A., \& Shamsudin, N. A. (2015). E-Learning and social media motivation factor model.

20. Schroeder, J., \& Greenbowe, T. J. (2009). The chemistry of Facebook: using social networking to create an online community for the organic chemistry laboratory. Innovate: Journal of Online Education, 5(4), 1-7.

21. Senthil-Kumaran, V., \& Sankar, A. (2013). Study of personalization in E-learning. International Review on Computers and Software, 8(5), 1209-1217.

22. Soares, D. A. (2008). Understanding class blogs as a tool for language development. Language Teacbing Research, 12(4), 517-533.

23. Terrell, J., Richardson, J., Hamilton, M. (2011). Using Web 2.0 to teach Web 2.0: a case study in aligning teaching, learning and assessment with professional practice. Australasian Journal of Educational Technology, 27(Special issue), 846-862.

24. Terry, H. (2017). The impact of social medi on history education: a view from England.

25. Tiene, C. D. (2000). Online Discussions: A Survey of Advantages and Disadvantages Compared to Face-to-Face Discussions. Journal of Educational Multimedia and Hypermedia, 9(4), 371-384.

26. Wheeler, S. (2010). Open content, open learning 2.0: using wikis and blogs in higher education. In U-D. Ehlers \& E. Schneckenberg (Eds.), Changing cultures in higher education: Moving abead to future learning (pp. 103-114). Heidelberg: Springer Berlin.

27. Yunus, M., Nordin, N., Salehi, H., Embi, M. A., \& Salehi, Z. (2013). The Use of Information and Communication Technology in Teaching ESL Writing Skills. English Language Teaching, 6(7), 1-8. 